\title{
Assessment of stope sequence alternatives in a diminishing ore pillar
}

\author{
S Shnorhokian McGill University, Canada \\ HS Mitri McGill University, Canada \\ L Moreau-Verlaan Vale Canada Ltd., Canada
}

\begin{abstract}
One of the primary mine planning abilities of numerical models is their assessment of stope sequence alternatives in terms of the redistribution of mining-induced stresses and the amount of rock face displacements in each of them. The models used for these studies are large and complex in nature as they need to replicate the entire orebody within which the stope sequence is being planned, in addition to the surrounding rock mass. In this paper, a case study is conducted at Vale's Garson Mine for the stope sequence options of mining in Orebody \#1 Shear West, which will result in a central diminishing ore pillar before final extraction. A mine-wide numerical model is first constructed in FLAC3D and calibrated based on an in situ stress measurement point on $4900 \mathrm{~L}(1,495 \mathrm{~m})$ such that the values read in the field are correlated to those generated by the model. The historical stope sequence followed at the mine is then replicated between the years 2001 and 2011, which is when mining is planned to commence between the levels of interest in \#1 Shear West. Extraction is planned from both the eastern and western sides of the orebody, and the default sequence is considered to alternate between the two in each successive step as they move towards the diminishing ore pillar. Using the brittle shear ratio - the relationship between the differential stress (sigma 1 to sigma 3) and unconfined compressive strength of intact rock - and volumetric analysis, the planned stope sequence is assessed within the diminishing ore pillar. A threshold of 0.7 is considered as indicative of ore at risk based on the literature and Vale guidelines. A second sequence alternative, in which extraction in the east is accelerated thrice, is also considered and compared with the planned one. A new stope sequence planning tool is introduced to visually and quantitatively compare amongst the two sequences. It is shown that by using the planning tool, the volume of unmined ore (of operational and economical interest) and the volume of ore at risk (of ground control interest) can be quantitatively estimated at any given mining step. Finally, variations in rock mass properties based on laboratory results and borehole logs are considered to assess their effect on the volume of ore at risk in the alternative sequence.
\end{abstract}

\section{Introduction}

Numerical modelling has become an integral part of the planning process in the mining industry, especially where an assessment needs to be made of the pre-mining and mining-induced stresses. Whether this is for a specific location of interest or on a mine-wide scale, the numerical model must first be calibrated based on field data such as in situ stress measurements or rock mass displacements. A calibrated model is able to provide current and future stress redistribution patterns based on planned mining activities, and indicate areas where they might converge to pose potential ground control challenges. Mine-wide models are especially useful to examine phenomena of a more global nature such as the stope sequence within an orebody or microseismic events that take place on the mine site. Naturally, these models are larger and more complex than the ones looking into local phenomena due to their incorporation of multiple geological units and structures, and are in most cases three-dimensional representations of the rock mass being modelled. The literature covers a wide array of uses for mine-wide numerical models in several practical applications within the mining industry. For example, researchers have examined microseismic activities with numerical models based on different approaches (Hazzard \& Young 2004; Marsan et al. 1999; 
McKinnon 2006; Mercer \& Bawden 2005a, b) such as seismic data analysis, statistical analysis, triggered seismicity, and clustering.

In this paper, a case study is conducted for Vale's Garson Mine in Sudbury with respect to a diminishing ore pillar between $5100 \mathrm{~L}(1,555 \mathrm{~m})$ and $4700 \mathrm{~L}(1,435 \mathrm{~m})$. A mine-wide numerical model is constructed in the finite difference code FLAC3D (Itasca Consulting Group, Inc. 2014), which is calibrated based on the correlation between an in situ stress measurement point on $4900 \mathrm{~L}(1,495 \mathrm{~m})$ and the generated readings at the same point within the model. The stope sequence followed at the mine is then replicated from 2001 to 2011 in three month stages. The planned stope sequence to be implemented in the future and an alternative sequence are then implemented from 2011 onwards, and studied in terms of differential stress levels.

\section{Garson Mine}

The case study for this paper is Vale's Garson Mine in Sudbury, which has been in operation for more than 100 years. The geology of the Sudbury Basin area is dominated by the series of formations designated as the Sudbury Igneous Complex, and Garson Mine is located at the southeast corner of the Basin. The deposits are mainly copper-nickel sulphides and are concentrated in two main orebodies designated as \#1 Shear and \#4 Shear, which are located at a depth of 1,200-1,700 m (4,000-5,600 ft), striking generally east-west and dipping $60-75^{\circ}$ to the south. The sheared host rocks are made up of metavolcanics and greenstone formations with norites to the north and metasediments to the south. All geological units are offset by a swarm of olivine diabase dykes in a northwest-southeast trend and one of them runs through

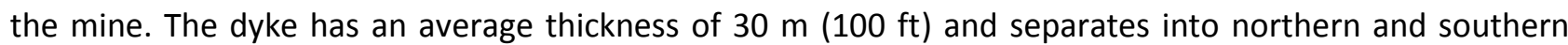
limbs prior to approaching the orebodies from the northwest. The north dyke runs parallel to the orebodies above the \#4 Shear, but the south dyke continues its northwest-southeast trend, dividing them into western and eastern sections. A shear zone about $15 \mathrm{~m}(50 \mathrm{ft})$ in width, designated as 2500 Shear, runs northwest-southeast almost parallel and close to the south dyke.

\section{$3 \quad$ Methodology}

The scope of the study for this paper comprises a diminishing ore pillar within \#1 Shear West between $5100 \mathrm{~L}(1,555 \mathrm{~m})$ and $4700 \mathrm{~L}(1,435 \mathrm{~m})$, which will eventually be extracted. A mine-wide numerical model is constructed for this purpose in FLAC3D, extending from $5100 \mathrm{~L}$ to $4470 \mathrm{~L}(1,365 \mathrm{~m})$, and comprising all the major geological units present. This specific code is chosen due to its ability to perform combined linear elastic and elastoplastic analysis of individual formations within a heterogeneous rock mass, its ability to replicate mine and backfill cycles, and its ability to incorporate dynamic analysis where required, a feature that is used in the other sections of the project.

The model is further extended to $5500 \mathrm{~L}(1,675 \mathrm{~m})$ and $3500 \mathrm{~L}(1,070 \mathrm{~m})$ in order to have the boundaries far from any of the extracted stopes. Figure 1 (a) presents an isometric view of the 3D model with the various geological formations and shows the locations of \#1 Shear West and \#1 Shear East, and Figure 1(b) shows the same view while highlighting the location and vertical extent of the orebody to be studied. A total of 1.15 million zones are used in the mine-wide model and it is run initially in linear elastic mode with a denser mesh within the regions of interest, becoming coarser towards the model boundaries. Stopes are constructed individually based on their unique geometries, with the group of stopes constituting a given orebody. This procedure greatly facilitates the extraction and backfilling process since each stope in the model can be mined out separately. 


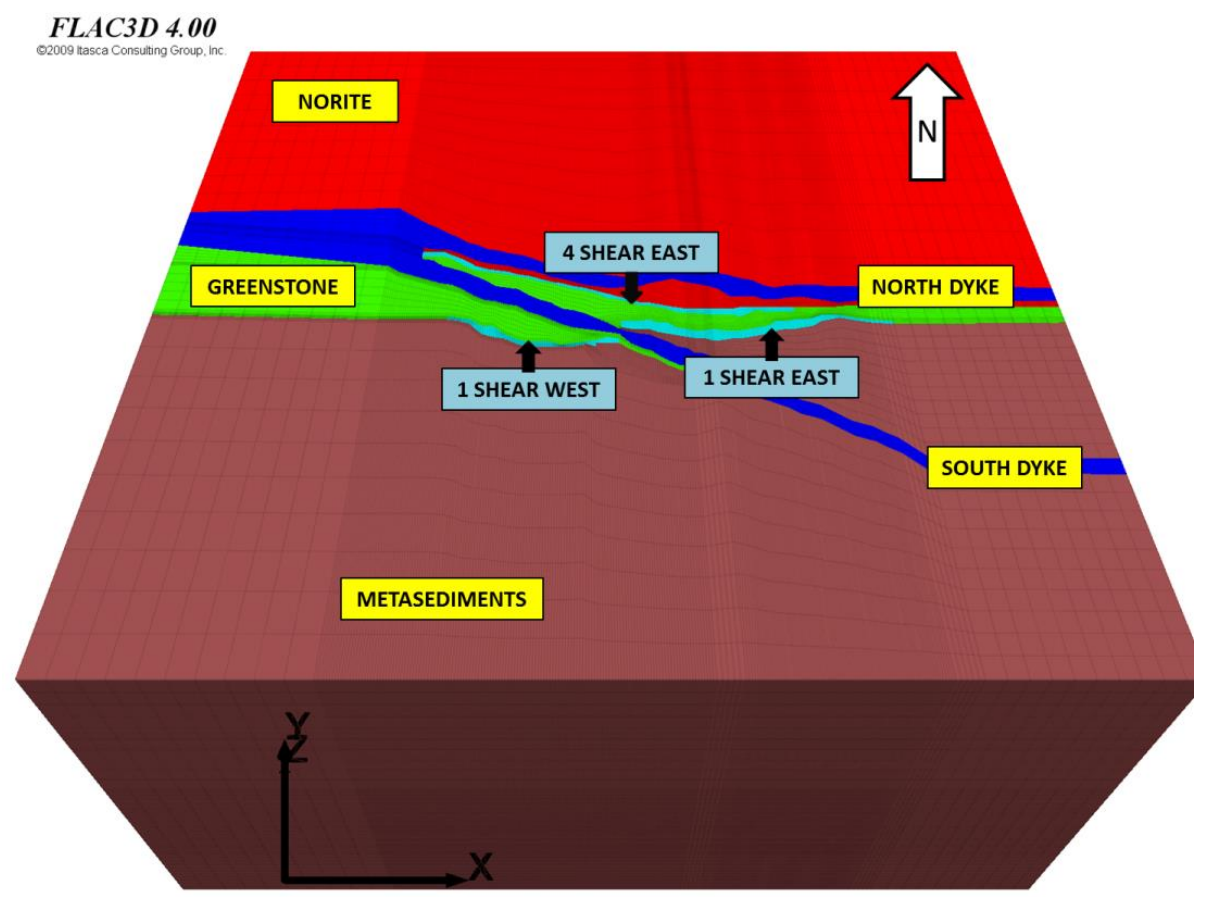

(a)



(b)

Figure 1 (a) isometric view of the mine-wide model of Garson Mine in FLAC3D; and (b) isometric view of the mine-wide model showing \#1 Shear West orebody

\subsection{Rock mass properties}

The rock mass properties used as input parameters for the numerical model are derived from a combination of laboratory tests conducted on intact rock samples (Suorineni \& Grasselli 2005) and borehole core log data. Parameters required for this study comprise the density, Young's Modulus $\left(E_{i}\right)$, Poisson's Ratio $(v)$, and unconfined compressive strength of intact samples (UCS intact), from which the rockmass $(E)$, bulk (K), and shear $(\mathrm{G})$ moduli needed by the code can be derived using Rock Mass Rating 
(RMR) values from the borehole logs, and the software RocLab (Rocscience inc. 2014) to conduct the calculations. The Geological Strength Index (GSI) is calculated by subtracting 5 from the RMR value as per the formula (Hoek et al. 1995):

$$
\mathrm{GSI}=\mathrm{RMR}-5
$$

Backfill properties are obtained from the literature (Li et al. 2003), and both rock and rock mass properties used are presented in Table 1.

Table 1 Rock and rock mass properties used in the numerical model

\begin{tabular}{|c|c|c|c|c|c|c|c|c|}
\hline \multirow[b]{2}{*}{ Geological unit } & \multirow[b]{2}{*}{$\begin{array}{l}\text { Density } \\
\left(\mathrm{N} / \mathrm{m}^{3}\right)\end{array}$} & \multicolumn{3}{|c|}{ Rock properties } & \multicolumn{4}{|c|}{ Rock mass properties } \\
\hline & & $\begin{array}{c}E_{i} \\
(G P a)\end{array}$ & $v$ & $\begin{array}{l}\text { UCS }_{\text {intact }} \\
\text { (MPa) }\end{array}$ & RMR & $\begin{array}{c}E \\
\text { (GPa) }\end{array}$ & $\begin{array}{c}K \\
\text { (GPa) }\end{array}$ & $\begin{array}{c}\text { G } \\
(\mathrm{GPa})\end{array}$ \\
\hline Greenstone & 31,088 & 99.5 & 0.23 & 172 & 71 & 65.0 & 40.12 & 26.42 \\
\hline Dyke & 29,567 & 132.2 & 0.26 & 195 & 71 & 86.3 & 59.93 & 34.25 \\
\hline Metasediments & 27,291 & 77.4 & 0.24 & 171 & 69 & 45.5 & 29.17 & 18.35 \\
\hline Norite & 28,380 & 83.7 & 0.25 & 163 & 72 & 56.4 & 37.60 & 22.56 \\
\hline Sulphide ore & 44,449 & 55.8 & 0.30 & 73 & 78 & 43.8 & 36.50 & 16.85 \\
\hline Backfill & 19,620 & 0.3 & 0.20 & 2 & - & - & - & - \\
\hline
\end{tabular}

\subsection{In situ stresses}

In situ stress measurements can be used to calibrate a numerical model provided they lie within the volume of rock mass it replicates. In their absence, the regional stress tensor can also be used although it will not be as accurate as the field measurements conducted specifically at the study site. With respect to Garson Mine, in situ stress measurements were conducted by Maloney and Cai $(2006)$ on $4900 \mathrm{~L}(1,495 \mathrm{~m})$ within the norite formation next to the north dyke. These values are used for calibrating the mine-wide numerical model by correlating them with the readings obtained from the model at the same location, which was done by using an approach to derive the required boundary tractions developed by the authors (Shnorhokian et al. 2014). The boundary conditions for the model are such that the bottom is restricted from movement in the $z$-axis direction while all the sides and the top are free except for the application of stress tractions. The target stress values at the calibration point on $4900 \mathrm{~L}$ and the readings obtained from the mine-wide model are presented in Table 2.

Table 2 Target values and model readings at calibration point on 4900 L

\begin{tabular}{ccccccc}
\hline Readings on 4900L (MPa) & SZZ & SYY & SXX & TXY & TXZ & TYZ \\
\hline Target values & 40.28 & 69.21 & 47.61 & 9.06 & 0.00 & 0.00 \\
Model readings & 40.33 & 69.01 & 47.60 & 9.03 & 0.01 & 0.15 \\
\hline
\end{tabular}

\subsection{Stope sequences}

The stope sequences are implemented in the mine-wide model in two phases. The first is the historical one from 2001 to 2011 whereby the actual extraction sequence that took place at the mine is replicated in stages of three months each. The second is the planned future stope sequence in \#1 Shear West and \#1 Shear East between $5100 \mathrm{~L}(1,555 \mathrm{~m})$ and $4700 \mathrm{~L}(1,435 \mathrm{~m})$ that continues from the point reached at by the historical sequence. The diminishing ore pillar appears towards the latter stages of planned mining in \#1 Shear West as extraction advances from both eastern and western sides towards the middle. Based on 
historical rates of production, three stopes are extracted and backfilled per stage of the planned sequence in \#1 Shear West, with the rest of the stopes allocated to \#1 Shear East.

The planned stope sequence is implemented in the numerical model after the historical sequence ends in 2011. Two different options are examined, which are designated as the original planned and alternative sequences. The original planned sequence alternates at each stage in stope extraction between the eastern and western sides of the orebody, and hence is called the one-to-one sequence. Due to the allocation of stopes to \#1 Shear West in each stage, three stopes are extracted from the eastern side in a given stage, followed by three stopes from the western side in the following one. The alternative sequence accelerates mining activities on the eastern side due to a larger volume of ore present there as per the orebody geometry. Three stages of mining take place on the eastern side (total of nine stopes) followed by a single stage on the western side, and hence it is called the one-to-three sequence.

Both sequence options comprise 36 stages at the end of which the entire \#1 Shear West is extracted between the levels of interest. Another common feature is that \#1 Shear East is extracted completely at Stage 33 in both sequences, which is to be expected as no changes are made to the extraction sequence or rate there. An important milestone is the stage at which the diminishing ore pillar extends from $5100 \mathrm{~L}$ to 4700 for the last time, at which point it would be at its narrowest and tallest dimensions. Due to the acceleration of mining on the eastern side in the alternative sequence, this takes place at different stages in the two scenarios. These are Stages 33 and 31 for the one-to-one and one-to-three stope sequences, respectively. In addition, the location of the diminishing pillar changes in each case, moving towards the west as mining is accelerated in the east. The location of the pillar at this milestone is presented in Figure 2 for each of the two sequence scenarios, where the location of the initial stages of mining is also shown graphically for both.

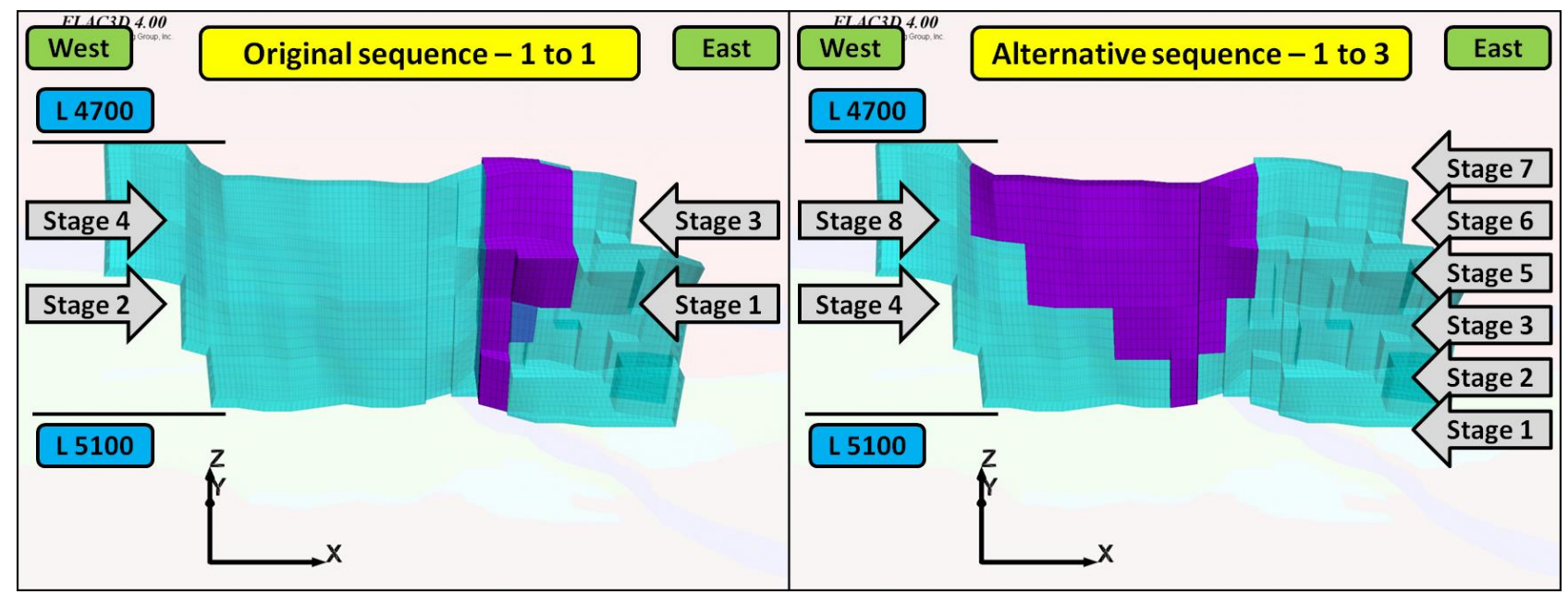

Figure 2 Location and shape of the diminishing pillar at its narrowest and tallest extent

\subsection{Mining-induced stresses}

The difference between the major and minor principal stresses gives the highest shearing effect possible, and it is an important parameter that is used frequently in the assessment of mining-induced stress within a rock mass (Castro 1996; Castro et al. 1997; Diederichs 1999; Martin et al. 1999). The maximum shear stress is half this differential stress as given in Equation (2) and the brittle shear ratio (BSR) is derived when the latter is divided by the unconfined compressive strength of an intact rock sample as presented in Equation (3) (Castro et al. 2012; Martin et al. 1999).

$$
\begin{gathered}
\left(\sigma_{1}-\sigma_{3}\right) / 2 \\
\left(\sigma_{1}-\sigma_{3}\right) / U C S_{\text {intact }}
\end{gathered}
$$


The maximum shear stress is one of the integrated outputs in FLAC3D, while a special code is written in the programmable language FISH to calculate the BSR at each stage. The results are obtained for both stope sequences and are used as the main basis of comparison amongst them for a number of reasons. Firstly, the BSR is more specific as it compares the differential stress to a constant value $\left(U C\right.$ S $_{\text {intact }}$ ) that is related to the particular geological unit in which it is measured. A certain stress level might not be problematic in one formation but pose a risk in another one with different properties. Secondly, guidelines are available in the literature as to what kind of instability or strainburst potential is associated with different ranges of the BSR. For example, Castro et al. (2012) indicate that values greater than 0.7 pose a major potential for strainbursting. Since Vale also uses a 0.7 threshold, the two stopes sequences are evaluated based on regions of ore within \#1 Shear West with BSR values greater than 0.7. These regions are designated as ore at risk, and their location, extent, and volume are assessed at each stage of mining for all three stope sequences.

\subsection{Volumetric analysis}

While the distribution and extent of regions with BSR values greater than 0.7 can be assessed qualitatively from a graphic presentation of the model results, a quantitative evaluation of the ore at risk is required to make an informed decision as to which of the sequences is more advantageous for mining operations. Therefore, a volumetric analysis is conducted for \#1 Shear West where the volume of zones - the smallest building blocks in the numerical model - with BSR values greater than 0.7 are calculated at each stage along with the volume of zones extracted during that stage, using the following formulae:

$\%$ of ore mined $=$ volume ore $\operatorname{mined} \times 100 /$ total volume ore in \#1 Shear West

$\%$ of ore at risk $=$ volume of ore at risk $\times 100 /$ total volume unmined ore

When the percentage of ore mined is plotted against the mining stage for the two stope sequences, it allows for an instant comparison amongst them as to how much of the ore has been extracted and how much of it still remains in place. When the percentage of ore at risk is plotted against the mining stage, it indicates the state of stresses within the ore that remains in place, and provides the percentage that has a BSR value greater than 0.7. The combination of the two in a single graph culminates in a stope sequence planning tool that can be used to visually, quantitatively, and simultaneously address issues of productivity and relative risk for multiple stope sequences.

\subsection{Variations in rock mass properties}

Rock samples obtained from multiple locations may give different results in the laboratory for the required test parameters. It is known that RMR or other rock mass properties may also greatly vary for a geological formation depending on the location and depth of sampling. Since these are used as input parameters for the numerical model, it becomes very important to understand the effect of such variations on the model output results. After conducting an initial parametric analysis, the rock mass properties of the orebody and greenstone units are observed to have the maximum impact on the differential stresses within the orebody and subsequently on the BSR. Hence, once the optimum stope sequence is determined as explained in the preceding section, two additional runs are conducted for that sequence in which the rock mass properties for the orebody and greenstone formations are reduced to a weaker state in order to generate lower and higher BSR values, respectively. The reduced rock mass properties are derived by combining the weakest laboratory result obtained for each of the two formations with their respective lowest RMR values from the borehole logs, and are presented in Table 3. Due to a single sample having been tested in the laboratory, the reduced rock mass properties of the orebody are derived by combining its results with a lower value of RMR obtained from the borehole logs. The software RocLab is used to combine unconfined compressive strength results (UCS intact), intact Young's Modulus $\left(E_{i}\right)$, and RMR to produce the required input rock mass properties.

The model is run in linear elastic mode in order to maximise stresses in the different geological units and obtain a conservative estimate of mining-induced stresses, and hence the maximum BSR, within \#1 Shear 
West. Since most of the major formations at the mine exhibit brittle behaviour, this is a valid assumption to make. However, in order to obtain realistic results within the orebody as well, and due to its more ductile behaviour as observed in the field, an additional run is conducted where the orebody is assigned average elastoplastic Mohr-Coulomb properties as presented in Table 3.

Table 3 Alternative rock mass properties for the orebody and greenstone formation

\begin{tabular}{|c|c|c|c|c|c|c|c|c|c|}
\hline \multirow[b]{2}{*}{ Geological unit } & \multicolumn{3}{|c|}{ Rock properties } & \multicolumn{6}{|c|}{ Rock mass properties } \\
\hline & $\begin{array}{c}E_{i} \\
(\mathrm{GPa})\end{array}$ & $v$ & $\begin{array}{l}\text { UCS }_{\text {intact }} \\
\text { (MPa) }\end{array}$ & RMR & $\begin{array}{c}E \\
\text { (GPa) }\end{array}$ & $\begin{array}{c}K \\
\text { (GPa) }\end{array}$ & $\begin{array}{c}\mathbf{G} \\
(\mathrm{GPa})\end{array}$ & $\begin{array}{c}\text { Cohesion } \\
\text { (MPa) }\end{array}$ & $\begin{array}{c}\phi \\
\left({ }^{\circ}\right)\end{array}$ \\
\hline \multicolumn{10}{|l|}{ Greenstone } \\
\hline Average: elastic & 99.5 & 0.23 & 172 & 71 & 65.0 & 40.12 & 26.42 & - & - \\
\hline Reduced: elastic & 43.0 & 0.19 & 36 & 43 & 6.5 & 3.51 & 2.75 & - & - \\
\hline \multicolumn{10}{|l|}{ Orebody } \\
\hline Average: elastic & 55.8 & 0.30 & 73 & 78 & 43.8 & 36.50 & 16.85 & - & - \\
\hline Reduced: elastic & 55.8 & 0.30 & 73 & 65 & 29.0 & 24.18 & 11.16 & - & - \\
\hline Average: Mohr-Coulomb & 55.8 & 0.30 & 73 & 78 & 43.8 & 36.50 & 16.85 & 6.1 & 42 \\
\hline
\end{tabular}

\section{$4 \quad$ Results and discussion}

Initially, the stope sequences designated as one-to-one (original planned) and one-to-three (alternative) are examined with respect to the mining-induced stresses at key stages. The BSR is used as the principal indicator and the threshold of 0.7 is used to designate areas of significant stress accumulation in the orebody. This occurs at a maximum shear stress of $25.5 \mathrm{MPa}$, based on the fact that it is the level at which the BSR becomes 0.7 within the orebody, indicating a major potential for strainbursting.

In order to make valid evaluations, this threshold is compared for both stope sequences and especially during the final stages, namely, from Stages 30 to 36 . A key milestone in each sequence is when the diminishing ore pillar is at its maximum height from $5100 \mathrm{~L}$ to $4700 \mathrm{~L}$ for the last time before mining on the

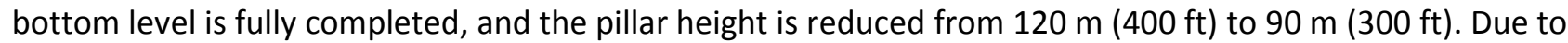
the different extraction rates on the eastern side, and the variation in the shape and location of the diminishing ore pillar, this milestone occurs at Stages 33 and 31 for the one-to-one and one-to-three stope sequences, respectively.

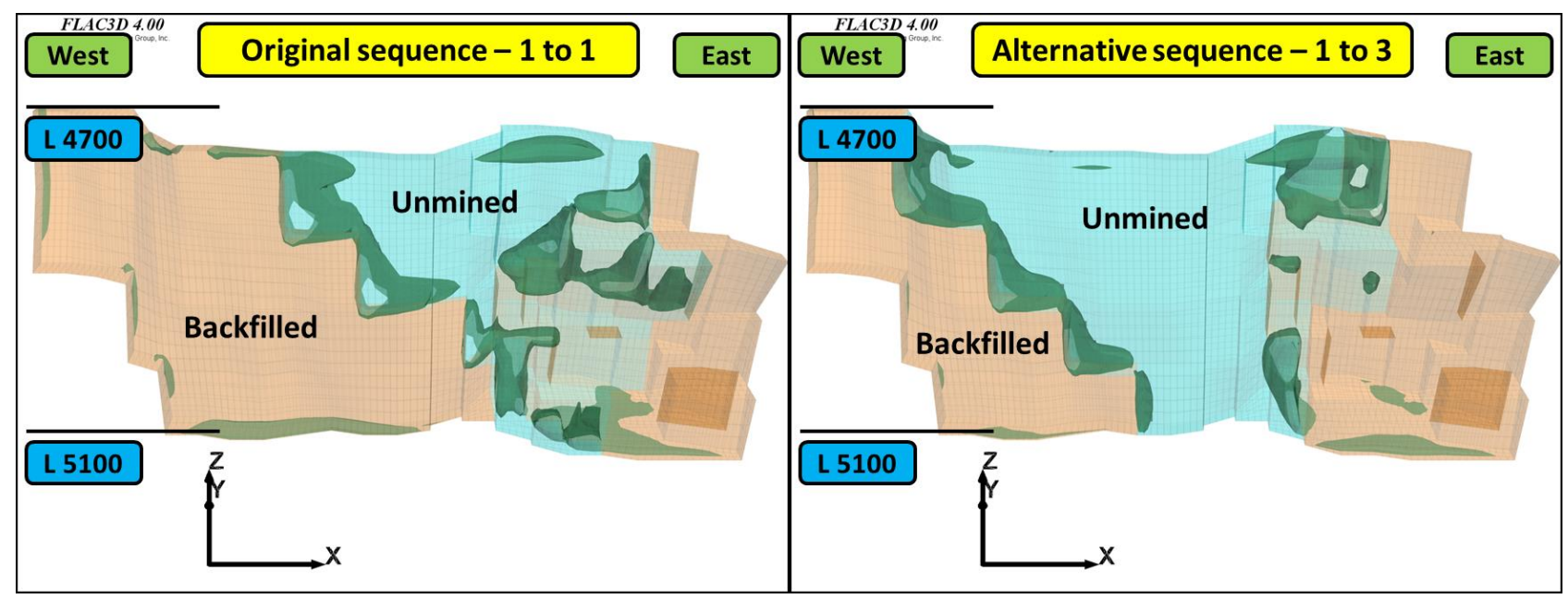

Figure 3 Stage 24: BSR exceeding 0.7 (green zones) in the two sequences with mined (orange) and unmined (light blue) stopes 
Figure 3 presents the BSR threshold at Stage 24 for the two stope sequence options, indicating zones with maximum shear stresses of $25.5 \mathrm{MPa}$ in green. It can be observed that volumes that exceed the BSR threshold are concentrated at the mining fronts and adjacent areas on all levels. The extent of this zone varies in the two sequences, being generally more voluminous in the original planned scenario. In the alternative sequence, a local concentration of ore with BSR values exceeding 0.7 occurs in the east between $4800 \mathrm{~L}$ and $4700 \mathrm{~L}$ while a more dispersed pattern can be seen in the west. In the original sequence, a concentrated pillar of elevated BSR zones is observed between $5100 \mathrm{~L}$ and $5000 \mathrm{~L}$ at the bottom, as well on the eastern front between $4900 \mathrm{~L}$ and $4800 \mathrm{~L}$. These are important comparative observations that, although expected due to the extent and geometry of the diminishing pillar in each sequence, confirm them based on numerical analysis.

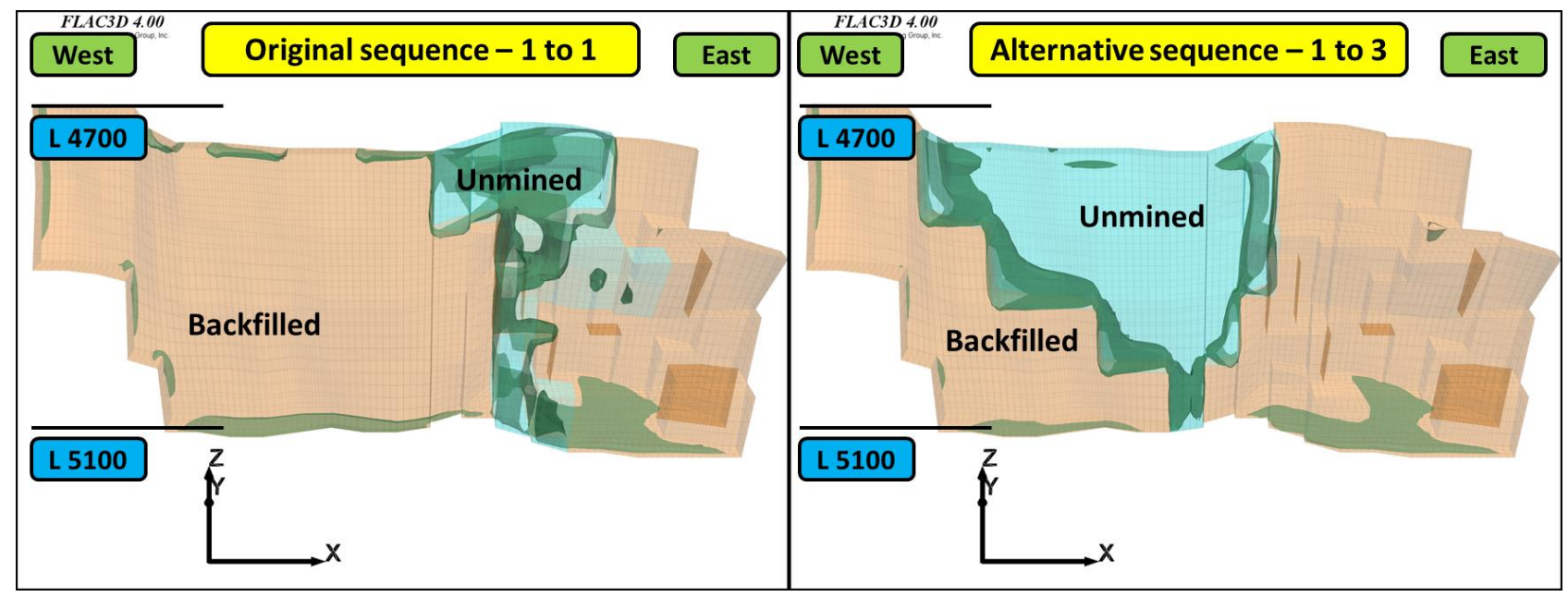

Figure 4 Stage 31: BSR exceeding 0.7 (green zones) in the two sequences with mined (orange) and unmined (light blue) stopes

Figure 4 presents the state of shear stress at Stage 31 for the one-to-one and one-to-three stope sequences bearing in mind that this is a milestone at which the diminishing ore pillar last extends from $5100 \mathrm{~L}$ to $4700 \mathrm{~L}$ in the latter scenario. In the alternative sequence, $5100 \mathrm{~L}$ is completely mined in Stage 32 while the same occurs in Stage 34 in the original sequence. The general pattern of the BSR threshold of 0.7 observed in Stage 24 is slightly modified in Stage 31. In the original sequence, most of the unmined ore above it is concentrated in the remaining pillar between $5100 \mathrm{~L}$ and $4900 \mathrm{~L}$, and dispersed towards the mining fronts in the upper levels. Only a few of the remaining stopes between $4900 \mathrm{~L}$ and $4800 \mathrm{~L}$ in the east are almost free of elevated BSR values. On the other hand, the volume of ore exceeding the threshold in the alternative sequence is still restricted to the mining fronts on both sides on all levels. Even though the pillar is at its narrowest between $5100 \mathrm{~L}$ and $5000 \mathrm{~L}$, the green zones are markedly smaller in size than in the original sequence. Hence, from a qualitative and location comparison of Stages 24 and 31, the alternative sequence is more advantageous in terms of volume of ore at risk and its location.

While the analysis conducted based on the relative volume and dispersion of ore at risk zones is useful, it nevertheless provides only a qualitative assessment of the two stope sequences. Since the visual evaluation sometimes provides comparable results, a more precise method of estimation is needed to determine the optimum solution quantitatively.

\subsection{Volumetric analysis}

The mine-wide numerical model is constructed in FLAC3D with quadrilateral blocks of the geological units, which are further subdivided into zones of variable size depending on the mesh density in that region. In order to conduct a more precise comparison amongst the two stope sequences, the percentage of ore extracted is calculated at each stage based on the total volume of ore present in \#1 Shear West between 5100L and 4700L (Equation (4) in Section 3.5). In addition, the percentage of ore at risk, which represents 
the volume with BSR values exceeding 0.7 , is monitored at each stage based on the total volume of unmined ore at that stage (Equation (5) in Section 3.5).

Figure 5 plots the volume of unmined ore within \#1 Shear West between the levels of interest for both stope sequences at each mining stage. The purpose is to evaluate the relative productivity of each option and the effect of accelerating mining operations in the east where the bulk of the ore is located. From the plots, it can be observed that the one-to-three sequence is the more productive option once extraction enters the final phase from Stage 24 onwards. The advantage of a visual and precise volumetric comparison is that a numerical value can be obtained for unmined ore at each stage, which is of great interest to operational and economic planners.

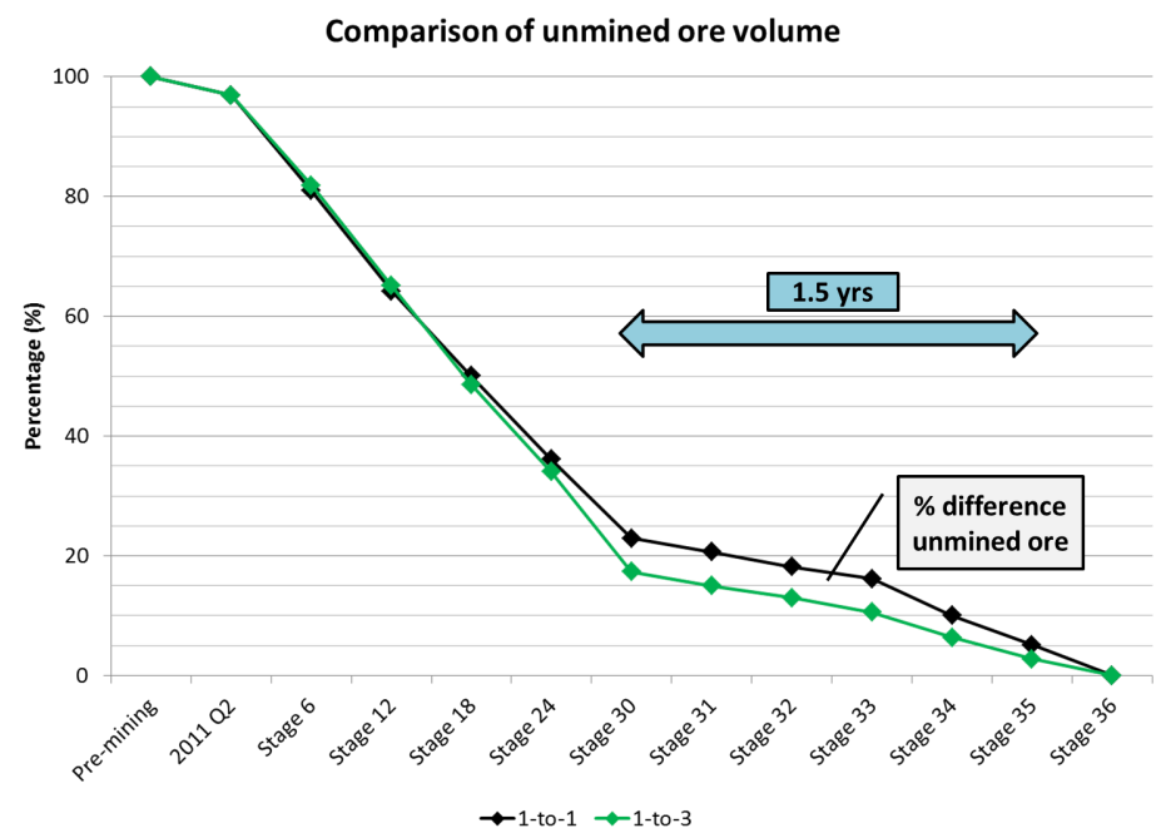

Figure 5 Percentage of unmined ore in the two stope sequences



Figure 6 Percentage of unmined ore at risk in the two stope sequences 
Figure 6 graphically presents the amount of ore at risk in the two sequences, indicating the relative volume of potentially problematic ore compared to the volume that is yet to be mined. This constitutes a vital comparison of the potential risk at each stage associated with each sequence. It should be noted that the volume of ore at risk is compared to the unmined ore, and not the total ore, and could therefore indicate how much of it is at risk at a given stage. For example, if mine management decides to undertake special ground support improvements beyond a certain threshold, the plots in Figure 6 could easily provide quantitative figures for this purpose. An evaluation of both sequences shows an appreciable difference in the volume of ore at risk from Stage 24 onwards. When the original planned option is compared against the alternative one, a $20-30 \%$ more volume of ore at risk is present from Stages 24 through 34 . This type of quantitative assessment for the various options is of prime interest to ground control teams.

Volumetric analysis is therefore able to provide constant monitoring and assessment of two important and quantifiable parameters at each stage of the two stope sequence options, which are the percentage of unmined ore in the region of interest, and the percentage of ore at risk with BSR values in excess of 0.7. The full potential of volumetric analysis, however, is realised when these two quantities are plotted in the same chart to produce a stope sequence planning tool.

\subsection{Stope sequence planning tool}

The percentages of unmined ore and ore at risk are combined in Figure 7 to constitute a useful stope sequence planning tool, which can simultaneously and quantitatively address multiple operational and ground control concerns. For example, a practical question when considering different stope sequences would be the volume of ore still in place when $50 \%$ of it is at risk with BSR values exceeding 0.7. From Figure 7, the answers can be read as 28 and $8 \%$, respectively, for the one-to-one and one-to-three sequences. Based on these values, it can be observed that the alternative scenario provides the better operational conditions in that $92 \%$ of the ore is already extracted by the time $50 \%$ of the remaining portion is considered to be at risk, as compared to only $72 \%$ in the original planned sequence.

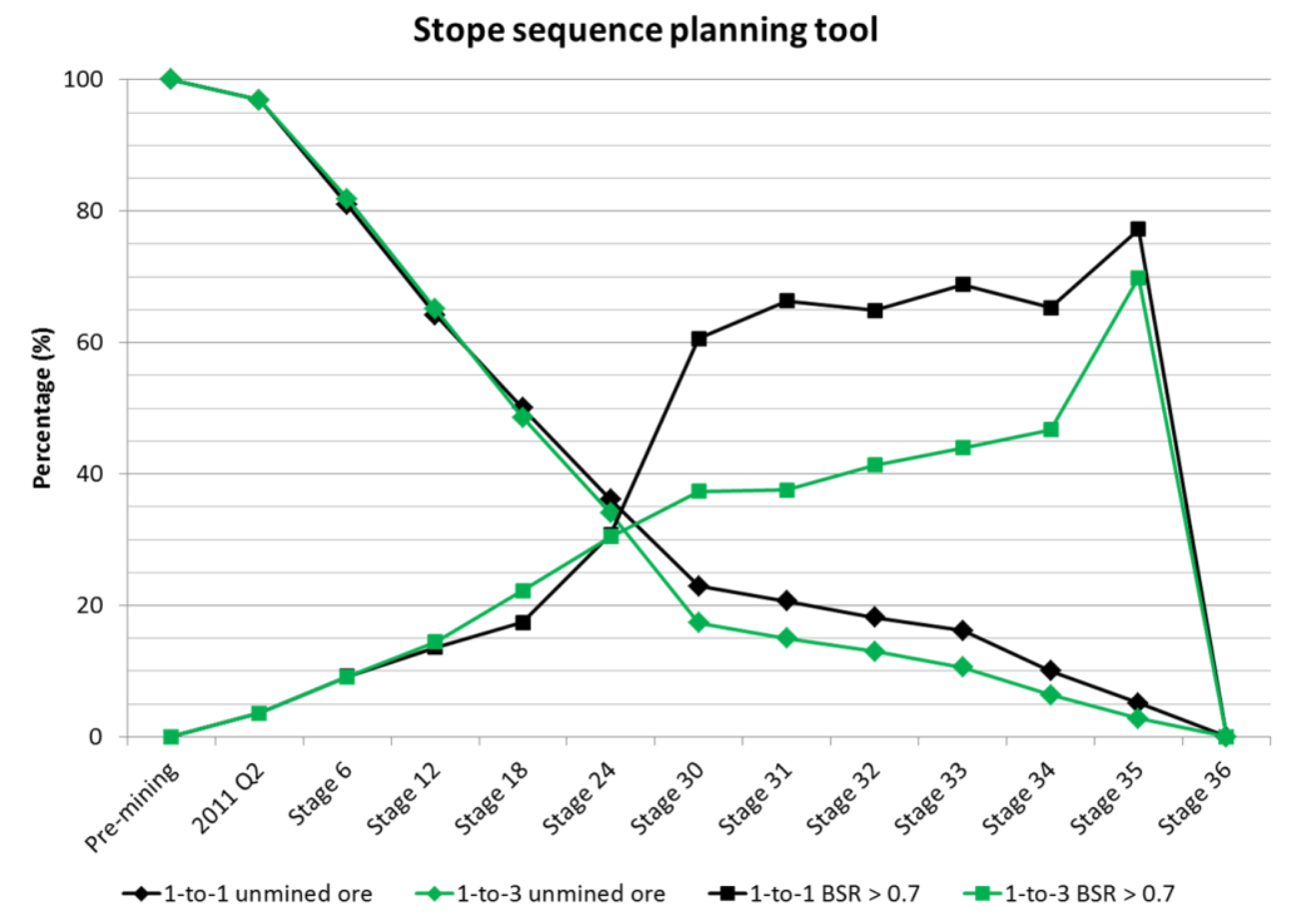

\section{Figure 7 Stope sequence planning tool}

Another query could be the percentage of ore at risk in the sequences when only, for example, $20 \%$ of unmined ore is left in the region of interest, so that operational and ground control teams can plan ahead for the final phase in terms of strategy and required ground support. From Figure 7, the answers can be 
readily retrieved as 66 and $35 \%$ for the original and alternative sequences, respectively. From a different perspective, this indicates that when $80 \%$ of the ore is mined, $66 \%$ of the portion still in the ground would be at risk for the one-to-one sequence, compared to only $42 \%$ for the one-to-three sequence. Hence, the alternative scenario provides better conditions in terms of ground control concerns.

A third and final example of practical applications for the tool is its ability to give the duration of a certain condition. For example, if it is decided to apply extraction operations with specifically deployed enhanced supports after a threshold of $50 \%$ of ore at risk is reached, the duration of the process needs to be known for cost estimation and its impact on profitability. From the chart, the duration during which $50 \%$ of the remaining ore is at risk can be read as 1.5 years (Stages 30 to 35) for the one-to-one sequence and three months (Stage 35) for the one-to-three option.

The stope sequence planning tool provides simple yet powerful visual assessments for the different options being studied regarding ore extraction. It can give quantitative answers to queries of an operational or a ground control nature, and objectively compare advantages to limitations. It is also flexible in that it can be modified to apply to a specific region of interest, a certain range of levels, or an entire orebody. In addition, there are no specific requirements or restrictions in terms of geological formations, ground conditions, or stope dimensions since the tool relies on two very basic outputs from a numerical model; volumetric data and maximum shear stress at each mining step, combined with the UCS of intact rock

\subsection{Variations in rock mass properties}

As indicated previously, variations in rock mass properties occur in nature as a result of local and regional heterogeneities in geological structures, and the evolution of various formations through time. The rock mass properties in Table 1 represent the average values for the geological formations at Garson and are obtained by combining laboratory test results with borehole log data for each one. In a related but separate parametric study, it was concluded that the highest levels of stress in \#1 Shear West were obtained when the greenstone formation was weaker in terms of rock mass properties, while the lowest levels of stress occurred when the orebody itself was weaker. Based on this information, and because of the results obtained in the previous sections, two additional model runs are conducted using the one-to-three stope sequence. In the first case, all the formations retain average rock mass properties while the greenstone formation is assigned values based on its weakest results obtained from laboratory tests and borehole logs. In the second case, the orebody properties are reduced to its minimum test values while all the other formations retain their average rock mass properties.

As indicated previously, all model runs are conducted in linear elastic mode to obtain maximum possible stress values, and therefore provide a conservative assessment through maximum BSR values within the orebody. Based on field observations, in which the orebody exhibits a ductile and less brittle behaviour, an additional run is conducted where all the formations are assigned their average linear elastic properties while the orebody is given average elastoplastic Mohr-Coulomb attributes. The objective of this part is to calculate a realistic BSR value and compare it with the conservative one obtained through the linear elastic approach. 


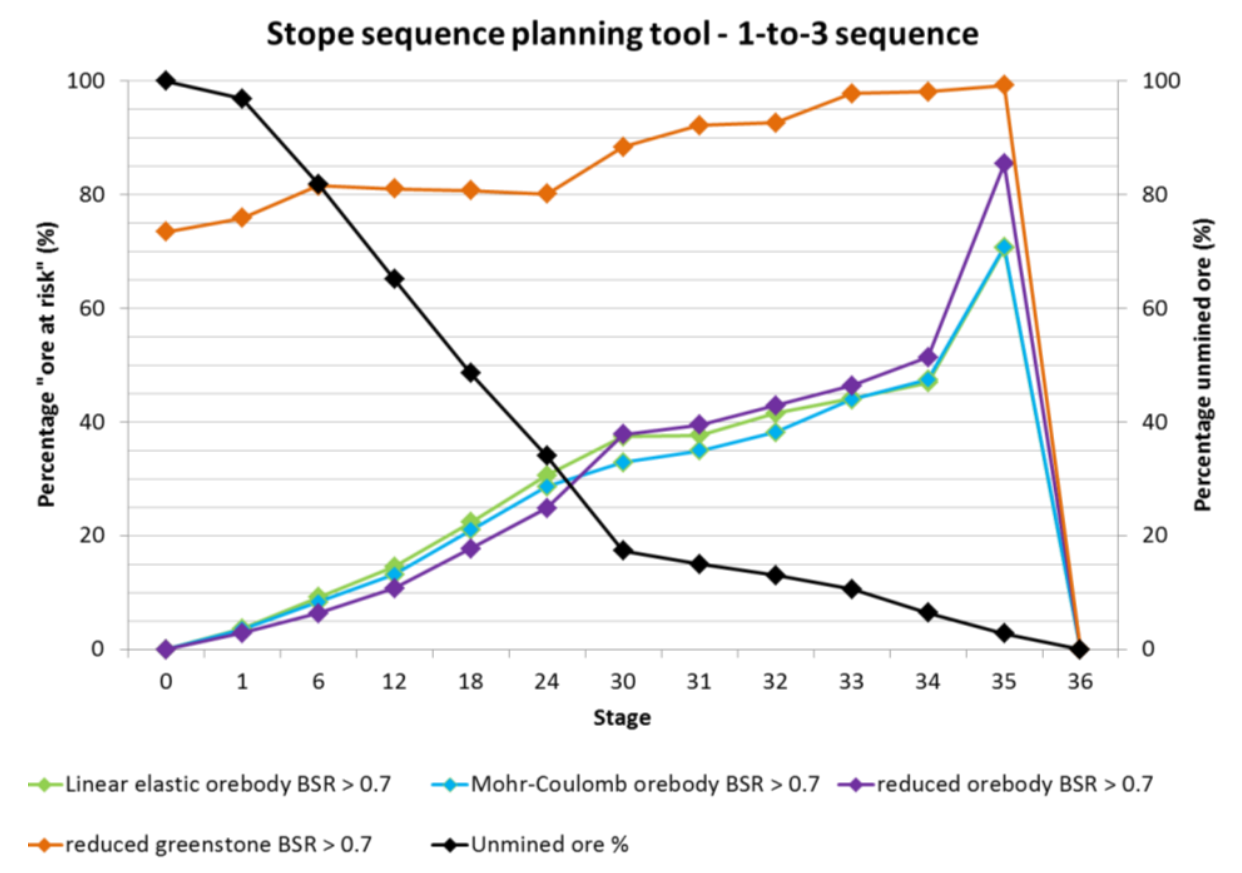

\section{Figure 8 Stope sequence planning tool for the one-to-three sequence: variations in rock mass properties}

Figure 8 plots the volume of unmined ore for the one-to-three sequence against the volume of ore at risk in the linear elastic one-to-three sequences with average, reduced greenstone, and reduced orebody properties, as well as the one in which the orebody is given average Mohr-Coulomb properties. It can be observed that in the case of a weak greenstone formation in linear elastic mode, the percentage of ore at risk, which is already high, increases to above $80 \%$ from Stage 6 onwards. The reason for this is that with the weakening of the greenstone formation, most of the stresses are carried by the more competent adjacent formations, which include the orebody, and this increases the stress levels - and therefore the BSR - there. In the second case, the orebody is weaker than its average value, and the results are almost comparable to the original case where its properties are at an average. The only notable difference is the higher volume of ore at risk at Stage 35, bearing in mind that until Stage 30, the percentage of ore at risk is slightly less than the average one-to-three sequence.

When the linear elastic one-to-three sequence with average properties is compared to the volume of ore at risk obtained with average Mohr-Coulomb ones, it can be observed that the two plots are not very different. As expected, the elastoplastic model provides slightly lower values of ore at risk throughout the stages with a maximum difference of $5 \%$, but it coincides with the linear elastic one from Stage 33 onwards. The linear elastic approach with average rock mass properties is used to obtain the maximum possible BSR ratio in the orebody throughout the different stages. The Mohr-Coulomb approach with average rock mass properties provides a comparison between the maximum possible and realistic BSR values, which are not far apart in this case.

The variations in rock mass properties are observed to be more dominant in determining the resultant BSR than the type of constitutive model used. From the two formations, it is observed that the properties of the greenstone unit are the major determining factor in the final BSR value. Hence, it can be concluded that with the identification of key geological units in a given case study, serious efforts must then be made to obtain as much realistic and local geomechanical data as possible in order for the models to be of practical use. Once the range of properties is clarified, stochastic approaches can also be employed to examine the confidence level in the percentage of ore at risk. 


\section{$5 \quad$ Conclusions}

A mine-wide numerical model is constructed in FLAC3D for Garson Mine in order to examine the stope sequence for a diminishing ore pillar in the \#1 Shear West orebody between $5100 \mathrm{~L}$ and $4700 \mathrm{~L}$. The model is calibrated based on a correlation with an in situ stress measurement point on $4900 \mathrm{~L}$ and based on the assignment of realistic rock mass properties derived from laboratory tests and borehole logs. An additional stope sequence in which mining is accelerated on the eastern side of the orebody is compared to the original one using volumetric analysis. Two parameters, namely, the volume of unmined ore and the volume of ore at risk with a BSR greater than $\mathbf{0 . 7}$, are used to compare between the two sequence options. It is observed that the alternative one where the mining rate in the east is three times the one in the west provides the more efficient approach with the lesser potential for strainbursts.

In order to examine the effects of rock mass properties on the volume of ore at risk, three additional runs are conducted with the alternative sequence. Models with reduced parameters for the greenstone and the orebody are studied individually, as well as a third one with average Mohr-Coulomb properties for the latter. It is observed that although slightly lower BSR values are obtained when the orebody is assigned Mohr-Coulomb properties, these are not markedly different than when linear elastic ones are used. The properties of the greenstone formation are seen to have the greatest impact on the BSR results. With a reduction in its strength, mining-induced stresses are observed to accumulate within geological units adjacent to the greenstone formation, including the orebody. A reduction in the properties of the latter generates only slightly lower values in the BSR in the initial stages and a minor increase towards the end.

\section{Acknowledgement}

This work is financially supported by a research grant from the Natural Sciences and Engineering Research Council of Canada in partnership with Vale Canada Ltd. (CRD Program). The authors are grateful for their financial support. Dr Denis Thibodeau, formerly principal consultant rock mechanics at Vale, is specially acknowledged for his support and technical input during the course of the project.

\section{References}

Castro, LAM 1996, 'Analysis of Stress-Induced Damage Initiation Around Deep Openings Excavated in a Moderately Jointed Brittle Rock Mass', PhD thesis, University of Toronto, Toronto.

Castro, LAM, Bewick, RP \& Carter, TG 2012 'An Overview of Numerical Modelling Applied to Deep Mining', in R Azevedo (ed.), Innovative Numerical Modelling in Geomechanics, CRC Press, London.

Castro, LAM, Grabinsky, MW \& McCreath, DR 1997, 'Damage initiation through extension fracturing in a moderately jointed brittle shear rock mass', International Journal of Rock Mechanics and Mining Sciences, vol. 34, no. 3-4, pp. 110e.1-e113.

Diederichs, MS 1999, 'Instability of Hard Rock Masses: the Role of Tensile Damage and Relaxation', PhD thesis, University of Waterloo, Ontario.

Hazzard, JF \& Young, RP 2004, 'Dynamic modelling of induced seismicity', International Journal of Rock Mechanics and Mining Sciences, vol. 41, no. 8, pp. 1365-1376.

Hoek, E, Kaiser, PE \& Bawden, WF 1995, Support of Underground Excavations in Hard Rock, Rocscience inc., Toronto, viewed 1 February 2014, http://www.rocscience.com/hoek/corner/Support_of_Underground_Excavations_in_Hard_Rock.pdf

Itasca Consulting Group, Inc. 2014, FLAC3D: Fast Lagrangian Analysis of Continua in Three Dimensions, Itasca Consulting Group, Inc., Minneapolis, http://www.itascacg.com/software/flac3d

Li, L, Aubertin, M, Simon, R, Bussière, B \& Belem, T 2003, 'Modeling arching effects in narrow backfilled stopes with FLAC', in P Andrieux, R Brummer, C Detournay \& R Hart (eds), Proceedings of the Third International Symposium on FLAC and FLAC3D Numerical Modeling in Geomechanics, CRC Press, London, pp. 211-219.

Maloney, S \& Cai, M 2006, In situ stress determination - Garson Mine, MIRARCO project report 06-015, Mining Innovation Rehabilitation and Applied Research Corporation, Sudbury.

Marsan, D, Bean, CJ, Steacy, S \& McCloskey, J 1999, 'Spatio-temporal analysis of stress diffusion in a mining-induced seismicity system', Geophysical Research Letters, vol. 26, no. 24, pp. 3697-3700.

Martin, CD, Kaiser, PK \& McCreath, DR 1999 'Hoek-Brown parameters for predicting the depth of brittle failure around tunnels', Canadian Geotechnical Journal, vol. 36, no. 1, pp. 136-151.

McKinnon, SD 2006, 'Triggering of seismicity remote from active mining excavations', Rock Mechanics Rock Engineering, vol. 39, no. 3, pp. 255-279.

Mercer, RA \& Bawden, WF 2005a, 'A statistical approach for the integrated analysis of mine induced seismicity and numerical stress estimates, a case study - Part I: developing the relations', International Journal of Rock Mechanics and Mining Sciences, vol. 42 , no. 1 , pp. $47-72$. 
Mercer, RA \& Bawden, WF 2005b, 'A statistical approach for the integrated analysis of mine induced seismicity and numerical stress estimates, a case study - Part II: evaluation of the relations', International Journal of Rock Mechanics and Mining Sciences, vol. 42, no. 1, pp. 73-94.

Rocscience inc. 2014, RocLab: Rock Mass Strength Analysis Using the Generalized Hoek-Brown Failure Criterion, Rocscience inc., Toronto, http://www.rocscience.com/products/14/RocLab

Shnorhokian, S, Mitri, HS \& Thibodeau, D 2014, 'A methodology for calibrating numerical models with a heterogeneous rockmass', International Journal of Rock Mechanics and Mining Sciences, vol. 70, pp. 353-367.

Suorineni, FT \& Grasselli, G 2005, 'Rock strength tests - Final report', Mining Innovation Rehabilitation and Applied Research Corporation, Sudbury. 